\title{
Sacralization of the Urban Footpath, with Special Reference to Pavement Shrines in Chennai City, South India ${ }^{1}$
}

\author{
YASUMASA SEKINE \\ Japan Women's University, Tokyo
}

\begin{abstract}
With regard to urban footpaths, there are two actors with different interests, the municipal authorities who, in theory, pursue town planning and maintain footpaths for the convenience of pedestrians, and the poor homeless living illegally on footpaths with the constant fear of being forced to leave. There exists a clear difference in stand-point between authorities and pavement dwellers on the use of footpaths: the former has a power to keep the public space free from encroachment but the latter finds the footpaths a space advantageous for living. The discussion focuses on pavement shrines that have become more ubiquitous in Chennai city, South India, since the 1990s and are mostly built and maintained by the socially and economically weaker sections of the city population. Footpath shrines may have and represent a power of resistance against authorities in the name of the sacred places they have been erected on, and are thus a weapon of the weak in their tactics for survival in the city. This ethnographic example holds an important theoretical connotation in terms of the emergence of a dynamic concept of sacred by suggesting that the edge or boundary of the dominant ideological social space or the boundary between the legal and the illegal in its context embraces a potentiality of producing sacrality, as is suggested by Veikko Anttonen's rethinking of the notion of sacred from the viewpoint of cognitive categorization.
\end{abstract}

Keywords: India, footpath shrines, sacred, social space

\section{Introduction: Footpath Space in Chennai City}

A quarter of the population of Chennai city, the capital of Tamil Nadu, the southern state of the Indian Union (the population of Chennai City Corporation was 4.2 million in 2001) are estimated to be slum dwellers. Since the economic liberalization of the 1990s, the flow of poor people into

\footnotetext{
${ }^{1}$ This article is based on the paper presented in The IAHR Congress, Tokyo, 23-31 March 2005, Panel on 'Religion, the Sacred and Spaces of Contestation, Segregation and Difference'.
} 
metropolitan cities such as New Delhi, Mumbai (Bombay), Kolkata (Calcutta) and Chennai (Madras) has been rapid. However, the capacity of the existing slums for accommodating newcomers is limited and, as a result, a considerable number of newcomers have become pavement or footpath dwellers. It is well-known that in Chennai city, people commonly walk at the edge of the roadway, not on the footpath, and therefore the footpath provides a sort of public open space of the city which anyone can access. In Chennai, slums often develop at open spaces along rivers, the seashore or by the side of railroads because ownership of these spaces is vested in government institutions. For the same reason, roadside locations have become a potential public space where houseless newcomers, that is, socially weaker people, can establish a livelihood. Footpath dwellers are often called homeless. But this expression seems to be incorrect, as most of these people live together with their family. This habit suggests that they are houseless not homeless. Moreover, the habit of living on the footpath does not look particularly unusual or abnormal, partly for the reason that it does not differ greatly from the custom of sleeping in the open air at pilgrimage centres, and partly for the reason that even people residing in houses may be seen sleeping outside at night, especially during summer.

Footpaths in Chennai city are very busy and lively. They brim with all sorts of behaviour, ranging from domestic (food, clothing and shelter) to social (the economic, political and religious) activities. The socially lower sections of the population play the leading role in the theatre of footpath space. For example, one day an auto-rickshaw driver living in a slum pointed towards a tree growing on an unpaved, dirt footpath and told me proudly: 'this is a papaya tree I planted'. 'Doing so is not unusual for us', he added. A bus-stop shelter on a footpath will sometimes be occupied by petty shopkeepers. A public toilet on a footpath may be transformed into a cow-shed. Posts with cinema-advertisement boards bristle on footpaths. Likewise, one often comes across 'pavement shrines' of different sizes built for the veneration of various deities at the edge of the wider roads across the city. One day you find that a Hindu deity like Lord Ganesha or a local goddess Amman is suddenly enshrined at the root of a big tree, such as a banyan or bo tree (the tree is reverently associated with the Great Buddha who meditated beneath such a tree and is believed to have attainted his enlightenment there) standing on the footpath, with people starting to worship there. This tiny shrine for a god or goddess consisting of a brick, a photo or a small idol, will gradually develop and in some cases reach the size of a mid-size regular shrine (with its own authorized compound), and will then fully occupy the 
footpath. Pavement shrine owners usually say that they built the shrine after they had had a dream in which a deity asked them to do so.

\section{Developing Stages of Pavement Shrines}

There are approximately 600 large and small regular shrines in Chennai. So far pavement shrines have not been counted. Our systematic sample survey conducted in 2000 gives an estimate of some 1600 pavement shrines in the city as a whole. On the basis of the survey, a native co-researcher, Prof. S. Subbiah of Madras University (Professor of Geography) and myself have reconstructed the several stages of the development of pavement shrines. I refer to Subbiah's description of the development in a paper he presented at the international workshop of ILCAA at Tokyo University of Foreign Studies.

There have been cases where shrines with structures come up over night. However, in many instances, the development occurs in stages, as it goes on unauthorized sites. First a demarcation with a few photographs of god with flower garlands on them is made in a place of prominence in the pavements. Promoter/s of this shrine may wait for a few days or months to find out whether there are any objections from people around or pedestrians or from the municipal authority or whether there is a support from the local residents; this is a breeding period; the construction of shrine in a small scale proceeds further, when there are no objections from any quarter. In the next stage, a firm hold is established; plants of neam and pupil may be planted in the demarcated area [Photo 1], and the area around gets cleaned with water and cow-dung every day. Then a permanent idol of god may be erected and a good concrete structure with roof may be built up. Now a collection box for collecting donations may appear in front of the shrine, and the promoters may start celebrating religious festivals with some elaborate arrangements by collecting money from the pedestrians and on-lookers and nearby houses and shop-keepers. If needed, shrine may further be expanded and the structure may have more decorations; this may be a final stage where it becomes a fully-developed shrine; Brahmin priest may get appointed to carry out daily rituals; and it may draw a large crowd and there may be regular visitors now. A 'little tradition' gets elevated to a 'great tradition'. Now here most of the Hindu festivals are held more regularly with a lot of fanfare, and this brings more life to the street and the area. A pavement shrine at this stage compares (competes?) with 'regular/public' shrines, and it is now a public shrine, illegally occupying a place in a public space, and owned and run by a private person or group. (Subbiah 2006, 84.)

The above mentioned stages of development of pavement shrines clearly show the concrete process of the sacralization of footpath space. 


\section{Globalization, Economic Liberalization and the Spread of Pavement Shrines}

The main highways of Chennai are radiated from George Town as the $\mathrm{CBD}$ of the city. The city is connected with the rest of the country by three national highways: Erukkancheri High Road leading to Calcutta and to the north, Poonamallee High Road leading to Bangalore and to the west, and Anna Salai (Mount Road) as the central axis of the city, linking the city with the districts to the south and southwest. Chennai city consists of a threelayered road system, that is, broad roads (salai), middle sized roads (theru) and small lanes (chandu).

Pavement shrines are found on either side of salai and theru. Most of these shrines face roads with rather heavy traffic and large numbers of pedestrians. The globalization or economic liberalization that has been ongoing for two decades has changed Indian society thoroughly. The social environment ranging from infrastructure to mass media has been revolutionized; capitalist consumerism has deeply penetrated peoples' lives; and flows of money, persons, things and information have escalated and accelerated.

According to our survey, one third of the pavement shrines existing at present were constructed during the last two decades. Those that were built before 1985 have also grown into a more elaborate stage of development. This phenomenon does not merely mark a simple coincidence in time between the progress of economic liberalization and the construction of pavement shrines but may also indicate a causal relationship. Socio-economic changes under economic liberalization have prepared the ground for and promoted the rapid increase and development of pavement shrines. This argument can be substantiated by considering the location of pavement shrines in two cases which will be explained later in this paper.

Without a substantial number of pedestrians passing along the footpaths, a pavement shrine may not be able to develop and cannot be maintained. The recent acceleration in the construction of pavement shrines and their visible development, especially after 1990, may thus partly be viewed as a reflection of the emerging revitalization of traditions and cultural 'heritage'. Furthermore it should be noted that this cultural revitalization was the result of one of the daily 'enterprises' undertaken principally by socially and economically disadvantaged people (Sekine 2006, 168-176). This 'enterprise' phenomenon displays a twisted relationship between pre-modern 'tradition' and post-modern new 'translation' (Robins 1991; Corner \& Harvey 1991). Even a tiny pavement shrine may be organized and exist at the crossroads between the 'heritage' of Tamil/Hindu cultural and religious tradition and 
the present 'enterprise' urge and motivation concomitant with the current of globalization.

\section{City Planning Authority and Pavement Shrine Construction: Negotia- tions for Survival}

It is obvious that where there are no broad roads bordered by footpaths, it would be impossible to observe a bricolage of pavement shrine construction. I am focusing on an ironical phenomenon taking place at the edge of socio-physical space. The construction of highways or wide roads - that is an important part of infrastructural development of the city - can be seen as a highlight or spectacle in the process towards modernization. Unless the city corporation executes top-down city planning, there would be no room for the bottom-up appropriation of footpath space for the purpose of building shrines. This paradoxical and illegal conduct (at least at the initial stage) of the lower sections of the population is obviously made possible because of the religious habitus embodied by Hindu Tamils/Indians. According to our survey, ordinary citizens generally appreciate the appearance of pavement shrines in the vicinity of their houses or offices, regardless of the legality of their status, because they are convenient for daily worship. Our survey shows that around 60 per cent of the pavement shrines enshrine Lord Ganesha, the god of beginnings and success and one of the most popular deities among Tamil people. It is interesting to note that Lord Ganesha tends to become the principal deity enshrined in pavement shrines, even though in many regular shrines Ganesha is positioned as a deity associated with, but secondary to, the main god. The fact that pavement shrines tend to adopt Ganesha as their main deity must follow from the tactics and strategies of the shrine owners to capitalize on the beliefs and sentiments of pedestrians and also the tolerance and acceptance of neighbours by catering to the cultural taste of the Tamil population.

With regard to urban footpaths, as mentioned above, two actors appear in opposite roles, namely on the one side the municipal authorities or city planners who pursue city planning and maintenance of footpaths for the convenience of pedestrians (in theory) and, on the other side, the marginal people or poor houseless residing illegally on footpaths with constant fear of being removed by the authorities at any time. The contrast of viewpoints of both actors can be compared to the difference between the 'strategy' adopted by those who look down and the 'tactics' conceived by those who walk on the ground (de Certeau 1984, 29-42). Needless to say, there is an irreconcilable difference between the viewpoint of the authorities and that of 
footpath dwellers in terms of the use of footpaths. No space is free from social power relations, and in this respect, urban spaces are seen as the intense locus reflecting the dynamism of power relations. Although city authorities as the stronger side exercise their power to keep the public space free from encroachments, the poor houseless, the weaker side, have no choice but to use footpaths as an advantageous space for living.

Since the second half of the 1990s, city planners and corporation authorities have been active in changing the profile of Chennai. Two main projects have been executed to that end. One is the programme of beautifying Chennai (Sinkara Chennai) and the other is the construction of fly-over bridges across busy junctions. These projects have seriously affected footpath dwellers in many parts of the city. This has been so because widening the roads has resulted in the trimming of footpaths, while the beautification of roads has entailed the removal of encroachments of all sorts. All these efforts towards the modernization of the city have instilled a strong motive among city planners and the public supporting them to eject footpath dwellers. Social tolerance with the illegal occupation of public space is therefore diminishing. Under these circumstances, the present paper looks at the latter weaker side in more detail. The discussion is focused on understanding how the poor are struggling for survival at the margins of both social and physical space. Footpaths, as the living space of the poor, look confusing, unclean and unpleasant, but they are also a lively place where people are, in fact, highly energetic and active. The struggle for survival on the space of the footpath is regarded as a protrusion or an ulcer within the socially ordered space from the point of view of the authorities. Thus, in Benjamin's sense (Benjamin 1969), footpaths in Chennai provide a typical example of an irregular place, a passive place and a place of the defeated. In the light of Benjamin's perspective, what should be done here is to extract the everyday creativities among the weaker section of people through their activities on footpaths that seem at first sight to be negative and hopeless.

\section{Resistance of the Weak: Tactics of Sacralization}

Toward the above-mentioned aim, I will provide three examples of pavement shrines before making some concluding comments.

\section{Example One}

Sakthi Muniswarar shrine, which faces east, is located at the crossing of Dr Radhakrihnan Salai and Royapettah High Road [Photo 2]. Since the middle 
of the 1990s, this shrine has grown from a tiny one into a larger one with a stone and concrete structure. At the beginning, the image of the god was at the edge of the footpath near the crossing, but, with a view to placing it in a better location, two men resituated it a little further in. When they touched the god, it is said, they were seriously injured as the god is very powerful, and they were admitted to hospital. Appreciating the power of the god, on their discharge from hospital, together with neighbouring residents, they put up a roofed shrine on the footpath. People then started to believe that, once the shrine was constructed, the god became satisfied and the residents and worshippers benefited. Once the shrine building expanded and the footpath formed part of the interior of the compound, the passers-by removed their footwear and started to pray. This shrine is also located under a huge bo tree. In 1998, concrete construction was over; in 2000, marble tiles were laid; and a billboard with electric light was fixed; then a bell was added. This is the process whereby the shrine was enlarged and established a permanent foothold on the path. The basis for development of this shrine is its location in front of the Tamil Nadu Electricity Board's local office, and this office gives a free supply of power to the shrine. People working there and visiting the office have been supporters of the shrine. There is no administrative committee but a non-Brahmin individual is in charge of its affairs of. Brahmin priests are invited only during festivals in the Tamil months of Tai and Adi.

\section{Example Two}

Nagathamman shrine at Nandanam, facing Anna Salai near its crossing with Venkatanarayana Road, is a very popular pavement shrine in that part of Chennai [Photo 3]. It receives its repute from enshrining a goddess with the power of working miracles. Nagathamman literally means snake goddess. People have a strong faith in her as the goddess who will provide for the fulfillment of any kind of prayers. The builder and owner of this shrine hails from the Vanniyar caste (one of the most backward communities), and resides in the neighbourhood. The religious power of this shrine is visibly obvious from the fact that only the location of the shrine on the footpath was left in tact while the footpath elsewhere was almost wholly removed for the widening of busy Anna Salai. Since the goddess faces Anna Salai, people pray to this goddess from the vehicular road. Immediately to the right side of this small shrine, there is a big bo tree and an ant-hill where a cobra is believed to be living and drinking the milk poured into the ant-hill by the devotees. This is contested by some rational people who say that the 
cobra probably comes from the poultry centre opposite the shrine and on the other side of the road. The eastern side of the tree (more precisely, the northeast) indicates the direction for praying, and still now a little shrine is extant as a remnant of the initial stage of the larger shrine's development. This reflects the belief that the root under the tree is the birth place of the goddess whose spirit was hovering around before becoming housed in the small but magnificent marble structure in front of the tree.

According to the Brahmin priest working there, this shrine has been in existence for the last 60 or so years. One of my native friends who lives in Chennai confirms that it must be older than 40 years according to his memory. Due to its significance, it can already be designated as a historical shrine. People faithful to this goddess visit the shrine on foot, by bicycle, by motorcycle or by car coming from different parts of the city and even beyond it. When I was there, I met a woman believer who was in distress and visited the shrine for the first time. She had heard about the power of the shrine from a person she had met at Melmaruvattur, where a shrine associated with the popular new religious movement of Adi Parashakti is located. Such personal communication among believers, who suffer from some distress, acts as a powerful medium in expanding the horizon of those who visit the shrine. When they worship, they spend most of the time in performing the action of a vow in front of the tree (a thread is folded around the tree nine times and tied; eggs are laid down without being broken). Finally they pray to the enshrined goddess and receive vibuthi (holy ashes, a white powder made from cow-dung) and sindur (a red powder made from turmeric) from the hired Brahmin priest. The shrine came under the legal protection of the Department of Hindu Religious and Charitable Endowments (HR\&CE) of the Government of Tamil Nadu in 1998. The billboard of the shrine displays the name of the shrine executor appointed by the Tamil Nadu Government and the shrine has now a legalized offering box (hundi) for the collection of donations. Twice a day in the morning and in the evening, poojas are performed by the Brahmin priest employed for the purpose. There will be large crowds on Fridays and at full moon. In the Tamil month of Adi (July), being special for the goddess, worshippers are more numerous. On these occasions, flower vendors and those selling items for offering to deities open their shops. In the vicinity of the shrine, there has been a large slum for the 50 or so years, as well as residential homes of those working in the film industry and a telephone office. These factors have contributed to widening the support base for the shrine and thereby enhancing its growth. Once such fervent belief is established, the small pavement 
shrine acquires sufficient popularity and power to allow resistance against the widening of roads by the city planning authority.

\section{Example Three}

There is a Yoga Muniswarar shrine facing to the east, built at the corner of a four-roads-crossing near Royapettah Hospital (a modern Western clinic) [Photo 4]. The shrine is devoted to the god with curative powers who is also believed to assist physicians in providing medical care. It seems to me that this location was very wisely chosen because while coming to or leaving the hospital, most patients will visit this shrine, due to their strong belief in the god. The shrine occupies a space about $4 \mathrm{~m}$ in width on the footpath. Its owners have been living there abutting the shrine wall for four generations. At present this shrine is administered by a widow who is in her $60 \mathrm{~s}$. She told me that she had inherited the shrine from her father. She herself was born and grew up at the site. She married and had two sons and two daughters who also grew up on the footpath. Her children married, and now she has eight grandchildren in all. All are living there. Her second son is an alcoholic and when I visited the place at noon, he was lying drunk in the shed. His wife being much disturbed by her husband's drinking, eventually committed suicide at the beginning of 2001. The size of the shed which is covered with blue plastic sheet has been reduced due to the pressure of the local area office of Chennai City Corporation. The city is filing a lawsuit against the family demanding their evacuation from the footpath. Under these conditions, the pavement shrine lends support to the family's struggle, as it continues to attract a large crowd of worshippers. Thus the family, consisting of three generations, is continuing to live together on the site, despite their fear of being driven away. They are precisely houseless but not homeless. The grandchildren are attending schools from their home on the footpath. They are engaged in pedaling cycle-rickshaws for hire, caning chairs and other small odd jobs. Their livelihood and place of living have largely been maintained by the shrine they own. It is true that the shrine, in addition to being a religious establishment, also provides an economic base. Even at the time of my interview, young well-dressed middle-class ladies visited the shrine for worship. The money put into the hundi by daily worshippers and the contributions collected from the neighbourhood during annual festivals are the income produced by the shrine. The money, thus collected, is used for holding festivals and the regular maintenance of the shrine, while part of the money is withheld for meeting household needs like food and clothes. Once a shrine is well established and becomes popular, 
it brings a good regular income and adds to the assets of the shrine owner. Such a well-developed pavement shrine, therefore, holds the value of real property. In the case of the owner's inability to maintain a pavement shrine, it will be sold to a new owner who will become the shrine administrator. Moreover, as the shrine provides shelter at times of heavy rains, it is a house for this poor family.

\section{Concluding Remarks}

These cases clearly show that sacredness or supernatural power derived from a resident deity is appropriated as the final resisting weapon of the weak against the overwhelming secular power determined to drive them away. Of course, this effect of the shrine is made possible under the premise of the common religious habitus shared by society.

Urban sociologist E. Anderson intensively investigated street life in a US metropolitan city and disclosed people's tactical knowledge which he referred to as 'street wisdom' (Anderson 1990). This wisdom is based on a 'code of violence' that contrasts with a 'code of decency' shared among citizens (Anderson 1999). Anderson deals with the change of social and spatial situations before and after the gentrification of zones in transition and zones of working people's homes just outside the CBD of the city. The change took place during the period of transforming an ordinary metropolitan city into a 'global city'. Although there is a big difference in terms of socio-cultural settings or people's habitus between Indian and US cities, Anderson's study and the present one share the common feature of dealing with phenomena during a similar period of change under the impact of globalization. Further, Indians and Americans live contemporaneous in a time when street culture or street wisdom seems to have a much stronger influence on them than before. For example, street fashion plays a significant role in generating new fashion, and it is actually taken in by major collection brands in Paris and New York. Today the creativity of street culture paradoxically appears to be quite significant. This experimental comparison supports the conclusion that what was shown by the practices of construction of pavement shrines may be regarded as a contemporary Indian variant of 'street wisdom'.

It seems to me that the incessant struggles for survival found among urban houseless on footpaths is thought of as a forerunning indication of what is taking place within ordinary householders' lives. The people today, regardless of whether they are house-dwellers or footpath-dwellers, can no longer be indifferent to 'street wisdom'. In other words, we have to face the reality that 'the fourth world' in Castells's sense (Castells 1998, Ch. 2) is a 
close and necessary part of 'the first world'. In this sense, a global city is 'a dual city' (Mollenkopf \& Castells 1992). This tells us that the 'street wisdom' emerging from the bottom must be a key wisdom for the 'multitude' in order to survive in a fluid or flexible society arising from the 'empire' type of globalization. It is, thus, productive and promising to focus on the new, bottom-up translation of traditional heritage at the edge of the dominant ideological social space (e.g. Duneier 1999).

Finally we gain a position where it is made possible to recapture the notion of sacrality or sacralization. The ethnographic example I examined here holds an important theoretical connotation in terms of the emergence of a dynamic concept of the sacred by suggesting that the edge or boundary of the dominant ideological social space or the boundary between the legal and the illegal in that context maintains a potentiality of producing sacrality. I believe that this comes closer to Veikko Anttonen's theoretical standpoint of a category-theoretical approach to religion, in which the notion of sacred is reconsidered in the terrain in local topography and redefined as a boundary phenomenon in the map of cognitive categorization (e.g. Anttonen 2005)

\section{Bibliography}

\section{Anderson, Elijah}

1990 Street Wise: Race, Class and Change in an Urban Community. Chicago: The University of Chicago Press.

1999 Code of the Street: Decency, Violence and the Moral Life in the Inner City. New York: W. W. Norton \& Company.

\section{Anttonen, Veikko}

2005 Space, Body, and the Notion of Boundary: A Category-Theoretical Approach to Religion. - Temenos 41(2), 185-201.

\section{Benjamin, Walter}

1969 Theses on the Philosophy of History. - Hannah Arendt (ed.), Illuminations, 253-264. New York: Schocken.

\section{Castells, Manuel}

1998 End of Millenium. The Information Age: Economy, Society, and Culture. Vol 3. Malden, Mass.: Blackwell Publishers.

\section{Corner John \& Sylvia Harvey}

1991 Introduction: Great Britain Limited. - John Corner \& Sylvia Harvey (eds), Enterprise and Heritage: Cross-currents of National Cultures, 1-20. London: Routledge 


\section{de Certeau, Michel}

1984 The Practice of Everyday Life. (Translated by Steven Rendall.) Berkeley: University of California Press.

\section{Duneier, Mitchell}

1999 Sidewalk. New York: Farrar, Strauss and Giroux.

Mollenkopf, John H. \& Manuel Castells

1992 Dual City: Restructuring New York. New York: Russell Sage Foundation.

\section{Robins, Kevin}

1991 Tradition and Translation: National Culture in its Global Context. - John Corner \& Sylvia Harvey (eds), Enterprise and Heritage: Crosscurrents of National Cultures, 21-44. London: Routledge.

\section{Sekine, Yasumasa}

2006 Contemporary Popular Remaking of Hindu Traditional Knowledge: Beyond Globalisation and the Invention of Packaged Knowledge - Christian Daniels (ed.), Remaking Traditional Knowledge; Knowledge as a Resource, 163-193. Tokyo: Research Institute for Languages and Cultures of Asia and Africa.

\section{Subbiah, S.}

2006 Religious Expressions of Urban Poor on Pavements and Religious Continuity of Overseas Indians: Some Observations from Chennai, India and San Francisco, USA. - Christian Daniels (ed.), Remaking Traditional Knowledge; Knowledge as a Resource, 75-123. Tokyo: Research Institute for Languages and Cultures of Asia and Africa 


\section{Appendix: Illustrations}

Photography by Yasumasa Sekine.

Photo 1 . The first stage of a pavement shrine; a very small neam tree is artificially planted at the foot of the big bo tree, because the combination of a $b o$ tree and a neam tree indicates an auspicious and sacred place.

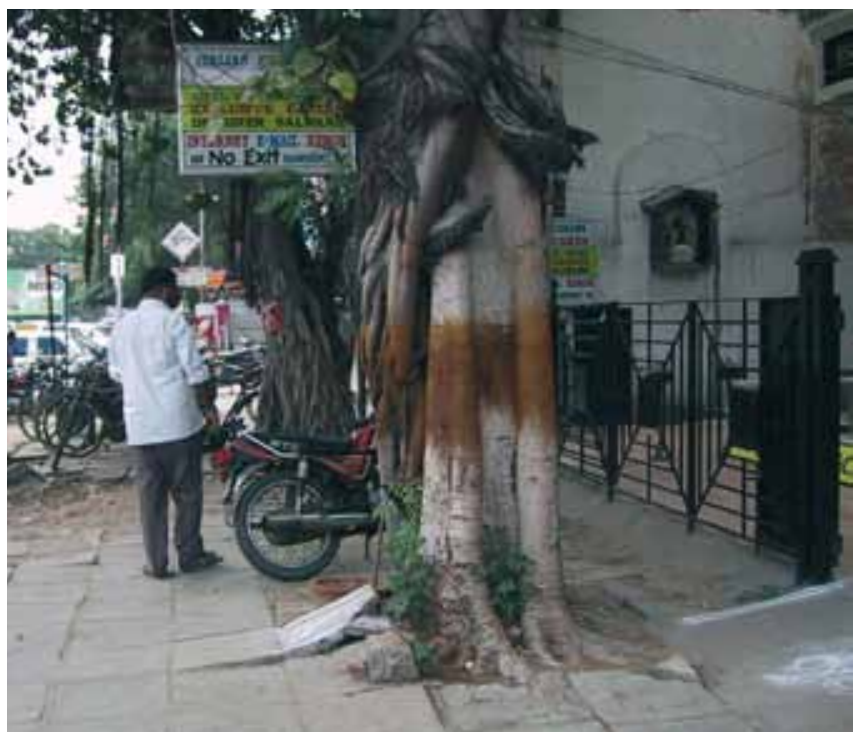

Photo 2. Sakthi Muniswarar shrine.

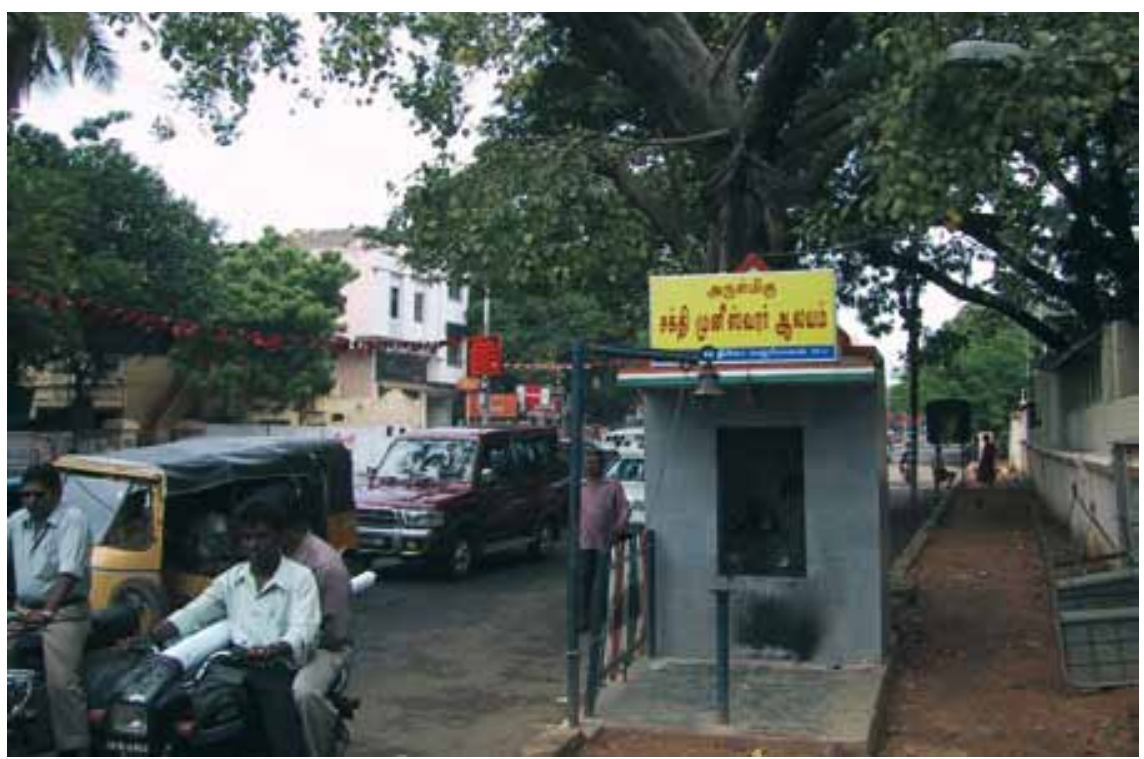


Photo 3. Nagathamman shrine.

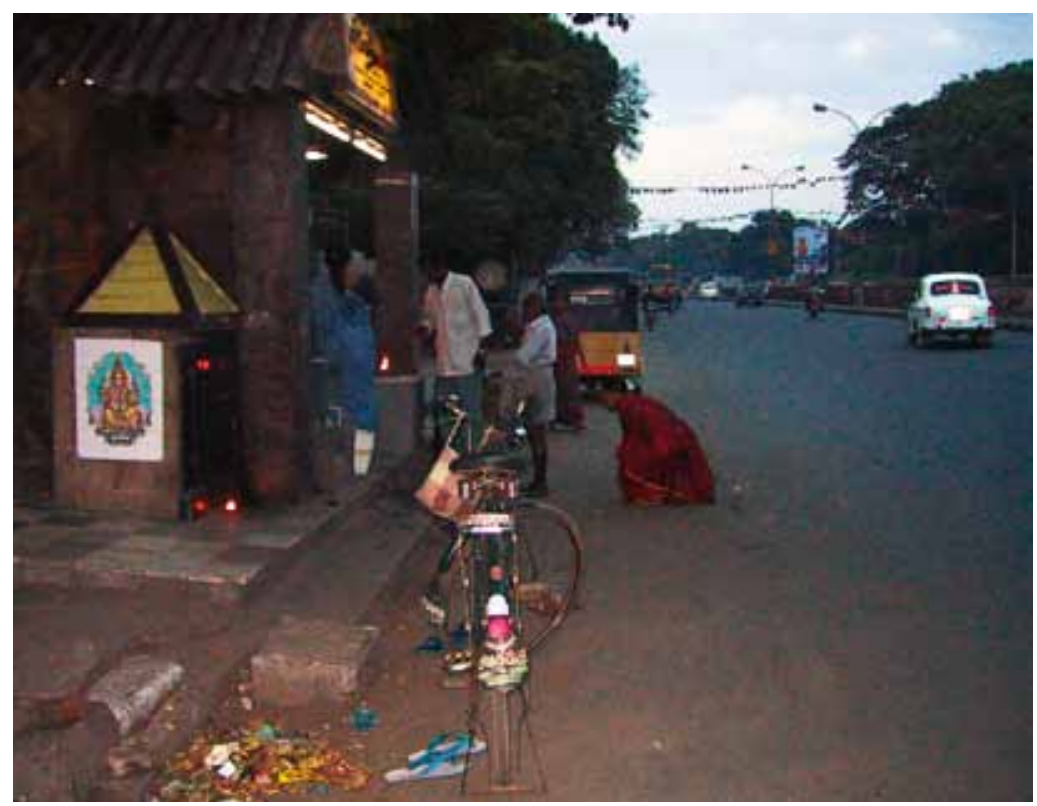

Photo 4. Yoga Muniswarar shrine.

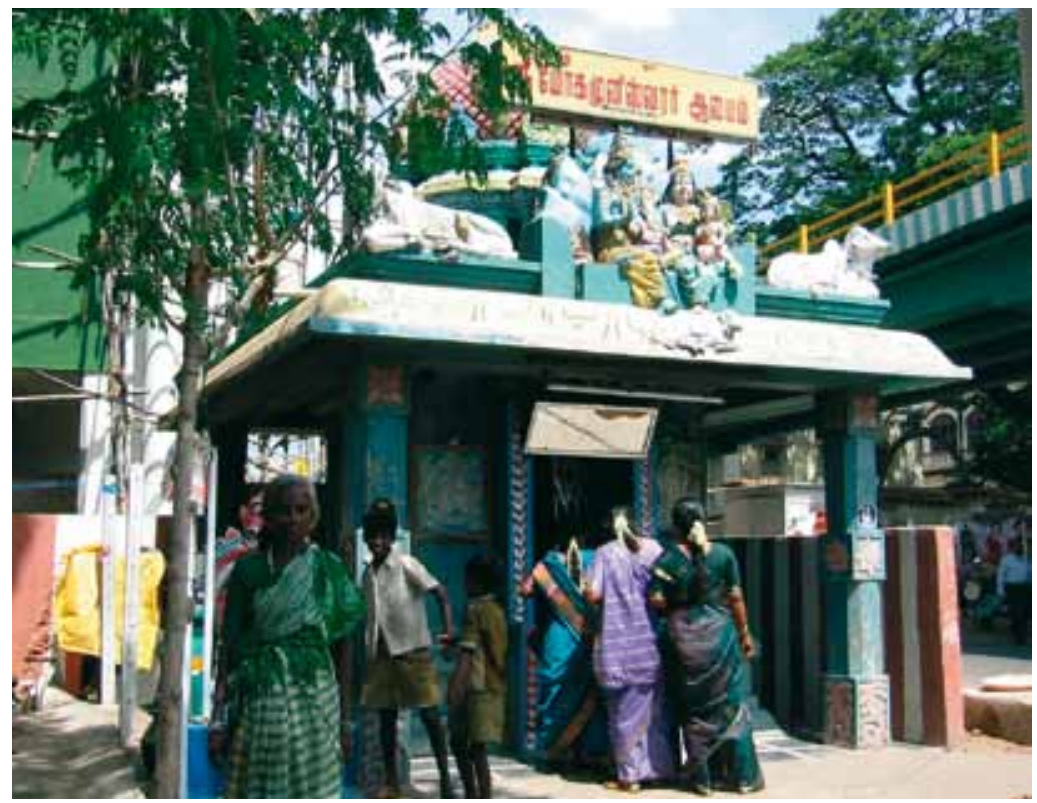

